\title{
BEE POLLEN ALLEVIATES FIPRONIL AND EMAMECTIN BENZOATE INDUCED- HEPATORENAL TOXICITY IN RATS
}

\author{
SALAH S. EL-BALLAL ${ }^{1}$; HANY A. AMER ${ }^{2}$; ENAS A. TAHOUN ${ }^{1}$; \\ NERMEEN B. EL-BORAI ${ }^{3}$ and MAHAMMED A. ABUO ZAHRA ${ }^{2}$ \\ ${ }^{1}$ Department of Pathology, Faculty of Veterinary Medicine, University of Sadat City, Egypt. \\ ${ }^{2}$ Department of Pathology, Animal Reproductive Research Institute, Egypt. \\ ${ }^{3}$ Department of Forensic Medicine and Toxicology, Faculty of Veterinary Medicine, University of \\ Sadat City, 32897, Egypt, Fax: 0020482603215
}

Received: 18 March 2019; Accepted: 7 April 2019

\begin{abstract}
Extensive use of pesticide has contributed to environmental pollution and adverse health effects to animals and humans. Fipronil (FIP) and emamectin benzoate (EMB), relatively new and widely used insecticides, are potent environmental toxicants. Therefore, the current study aimed to investigate the protective role of bee pollen suspension (BPS) against FIP- and EMB- induced hepato-renal toxicity in rats. Rats were randomly allocated into six equal groups and treated orally, 3 times weekly for 8 weeks; control group (distilled water),BPS group $(120 \mathrm{mg} / \mathrm{kg})$, FIP group $(9.7 \mathrm{mg} / \mathrm{kg})$, EMB group, $(8.8 \mathrm{mg} / \mathrm{kg})$, BPS+FIP group (BPS one h before FIP) and BPS+EMB group (BPS one $h$ before EMB). The results revealed that FIP and EMB significantly increased serum ALT, AST activities; urea and creatinine levels. Also, there were substantial increases in the liver and kidney malondialdehyde level, reduced glutathione content and catalase activity. Moreover, FIP and EMB caused histopathological alterations in liver and kidney tissues. However, pretreatment with BPS one hour either before FIP or EMB administration ameliorated all the biochemical and histopathological changes indicating its antioxidant properties. In conclusion, BPS can be used as a new preventive supplement against toxic insults of FIP and EMB.
\end{abstract}

Key words: Fipronil, Emamectin benzoate, Bee pollen, Histopathology, Antioxidant.

\section{INTRODUCTION}

Pesticides including insecticides, fungicides, herbicides, rodenticides, and others, are being used extensively throughout the world for controlling agricultural, industrial, domestic and public health pests (Bjorling-Poulsen et al., 2008). The injudicious use of pesticides exerts immense environmental pollution and health hazards to target and non-target organisms (Noaishi et al., 2013). Among them, fipronil and emamectin benzoate, relatively new insecticides, are of a new area of research.

Fipronil (FIP), a phenylpyrazole broad-spectrum insecticide, is widely used in various residential, agricultural and veterinary applications, particularly, against insects that are resistant to pyrethroids, organophosphates, and carbamates (Tingle et al., 2003; Brassard et al., 2011).

Fipronil, a neurotoxic insecticide, is a potent gammaaminobutyric acid (GABA) gated chloride channel inhibitor and possesses a favorable selective toxicity

Corresponding author: Dr. NERMEEN B. EL-BORAI E-mail address: nermeenborai@yahoo.com

Present address: Department of Forensic Medicine and Toxicology, Faculty of Veterinary Medicine, University of Sadat City, 32897, Egypt, Fax: 0020482603215. towards insects rather than mammals (Stanley et al., 2012). Besides being a neurotoxic agent, FIP exerts hepato-renal (Mossa et al., 2015), development (de Barros et al., 2016), reproductive (de Barros et al., 2017), mutagenic (de Oliveira et al., 2012) and carcinogenic (Jackson et al., 2009) effects.

Emamectin benzoate (EMB), a semi-synthetic derivative of a second-generation avermectin insecticide, is naturally produced by fermentation of the soil bacterium Streptomyces avermitilis (Ioriatti et al., 2009). It is extensively used in agro-vet sectors (Castanha Zanoli et al., 2012).

EMB acts as GABA-gated chloride channel activator leading to an increase in membrane chloride-ion permeability, leading to nerve membrane depolarization and eventually blocking the nerve impulse conduction resulting in irreversible paralysis (Jansson and Dybas, 1997). Moreover, EMB possess neuro- (Wise et al., 1997), hepato-renal (KhaldounOularbi et al., 2015, 2016) and developmental (Gabr et al., 2015) toxic effects.

Both fipronil and emamectin induce oxidative stress in different organs, mediated by increasing reactive oxygen species (ROS) production and decreasing the intracellular antioxidants (Badgujar et al., 2015; 
Mossa et al., 2015; El-Sheikh and Galal, 2015), resulting in damage of cellular macromolecules including lipid, protein and DNA.

Because of the implication of oxidative stress in health problems induced by a variety of environmental pollutants, including insecticides, much effort has been expanded in studying the potential ameliorative effect of natural herbal medicine against such toxic effects.

Pollen grains are apicultural honeybee products rich in biologicaly active substances, including, proteins, amino acids, carbohydrates, lipids and fatty acids, polyphenolic compounds, enzymes, vitamins and bioelements. Pollen and pollen products are valuable traditional herbal medicine widely used in the treatment of various diseases as it has many pharmacological properties including antimicrobial, anti-inflammatory and analgesic effects (Komosinska-Vassev et al., 2015). Furthermore, previous studies proved the immune-stimulant, antioxidant, antimutagenic, hepato-renal protective properties of bee pollen (El-Bialy et al., 2016, Huang et al., 2017, El- Borai et al., 2018).

Set against the background of the risk of indiscriminate exposure to insecticides and the health hazards effect to animals and humans. This study was designed to evaluate the potential protective role of bee pollen suspension against fipronil- and emamectin benzoate- induced hepato-renal toxicity in rats.

\section{MATERIALS AND METHODS}

\section{Experimental Animals:}

Sixty mature healthy male albino rats (150-170 g) were obtained from the Animal House of Food Technology Research Institute, Agricultural research Center, Giza, Egypt. Rats were housed in polypropylene cages with mesh wire tops and kept in a natural ventilated room $\left(25 \pm 3{ }^{\circ} \mathrm{C}, 45-60 \%, 14 \mathrm{~h}\right.$ light/ $10 \mathrm{~h}$ dark cycle), provided with standard commercial diet and clean tap water ad libitum. Rats were acclimatized to the laboratory environmental conditions for 2 weeks prior to the start of experiment. The study was ethically approved by the International Animal Care and Use Committee (IACUC), Faculty of Veterinary Medicine, University of Sadat City.

\section{Chemicals:}

Fipronil (Fipromex ${ }^{\circledR} \quad 20 \%$ EC, MAC-GmbH, Company, Germany) and Emamectin benzoate (Emamex ${ }^{\circledR} \quad 5 \%$ EC, MAC-GmbH, Company, Germany) were commercially available. Bee pollen was purchased from apiary at Sadat City, Egypt. Diagnostic kits for assaying serum and tissue biomarkers were purchased from Biodiagnostic
Company, Dokki, Giza, Egypt. Other utilized chemicals were of analytical grade and commercially available.

Preparation of bee pollen suspension (BPS):

Bee pollen grains were grinded carefully to obtain fine powder. The aqueous suspension was freshly prepared daily by adding distilled water to the powdered bee pollen with stirring for 10 minutes on a magnetic stirrer till complete dispersion (Mehraban et al., 2014).

\section{Experimental Design and Animal Grouping:}

Rats were weighed, randomly allocated into six equal groups and treated orally, 3 times weekly for 8 weeks. Control group, rats were orally administered distilled water. BPS group, rats were orally administered BPS at $120 \mathrm{mg} / \mathrm{kg}$ b.w. (Mehraban et al., 2014). FIP group, rats were orally administered FIP at $9.7 \mathrm{mg} / \mathrm{kg}$ b.w. EMB group, rats were orally administered EMB at $8.8 \mathrm{mg} / \mathrm{kg}$ b.w. BPS+FIP group, rats were administrated BPS one hour before FIP administration. BPS+EMB group, rats were administrated BPS one hour before EMB administration. The selected doses of FIP and EMB were $1 / 10$ of oral $\mathrm{LD}_{50}$ of FIP $(97 \mathrm{mg} / \mathrm{kg} \mathrm{b.w})$ and EMB (88 mg/kg b.w.) in rats (Tingle et al., 2003 and Gabr et al., 2015).

\section{Samples Collection:}

At the end of the experiment, rats were fasted overnight, anaesthetized and sacrificed for samples collection. Blood samples were collected in clean and dry glass centrifuge tubes for serum collection and then stored at $-20^{\circ} \mathrm{C}$ for further serum biochemical analysis. Liver and kidney of each rat were collected and divided into two parts, one part was packed in ice bags at $-20^{\circ} \mathrm{C}$ for tissue biochemical analysis, while other parts was fixed in $10 \%$ neutral buffered formalin solution for the histopathological investigation.

\section{Serum Biochemical Analysis:}

Serum ALT and AST activities (Reitman and Frankel, 1957); urea (Fawcett and Soctt, 1960) and creatinine (Schirmeister, 1964) levels were estimated using commercial kits.

\section{Oxidant/ antioxidant biomarkers:}

Malondialdehyde (MDA) and reduced glutathione (GSH) levels and catalase (CAT) activity were measured in liver and kidney tissue homogenates according to Ohkawa et al. (1979), Beutler et al. (1963) and Aebi (1984), respectively, using commercial kits.

\section{Histopathological examination:}

Following necropsy, tissue specimens from liver and kidneys were collected and rapidly fixed in $10 \%$ neutral buffered formalin solution. The fixed 
specimens were trimmed, washed, dehydrated in ascending grades of ethyl alcohol, cleared in methyl benzoate and processed through the conventional paraffin embedding technique. 3-5 $\mu \mathrm{m}$ sections were obtained from paraffin blocks using microtome (LEICA RM 2135) then routinely stained by hematoxylin and eosin ( $\mathrm{H} \& \mathrm{E})$ stain according to Bancroft et al. (1996) and crossman'strichrome stain according to Crossman (1937). Stained slides were microscopically analyzed using light microscopy. Histopathological Photos were photographed using a digital Leica photomicroscope (LEICA DMLB Germany).

\section{Statistical Analysis:}

Values are presented as mean \pm standard error (SE). Statistical significance of data was determined by one-way ANOVA (Analysis of Variance) followed by Duncan's Multiple range test for post hoc analysis.
All statistical analyses were performed using SPSS (Statistical Package for Social Sciences) Version 16 released on 2007.

\section{RESULTS}

\section{Tissues oxidant/ antioxidant biomarkers:}

No significant variations $(P<0.05)$ were observed concerning the hepatic and renal MDA and GSH levels; CAT activity between control and BPS groups. Fipronil and emamectin benzoate were able to significantly increase hepatic and renal MDA level and decrease GSH content and CAT activity, compared to control group. Administration of BPS either with FIP or EMB ameliorated these toxic effects and restored the normal control values of all parameters (Fig. 2).
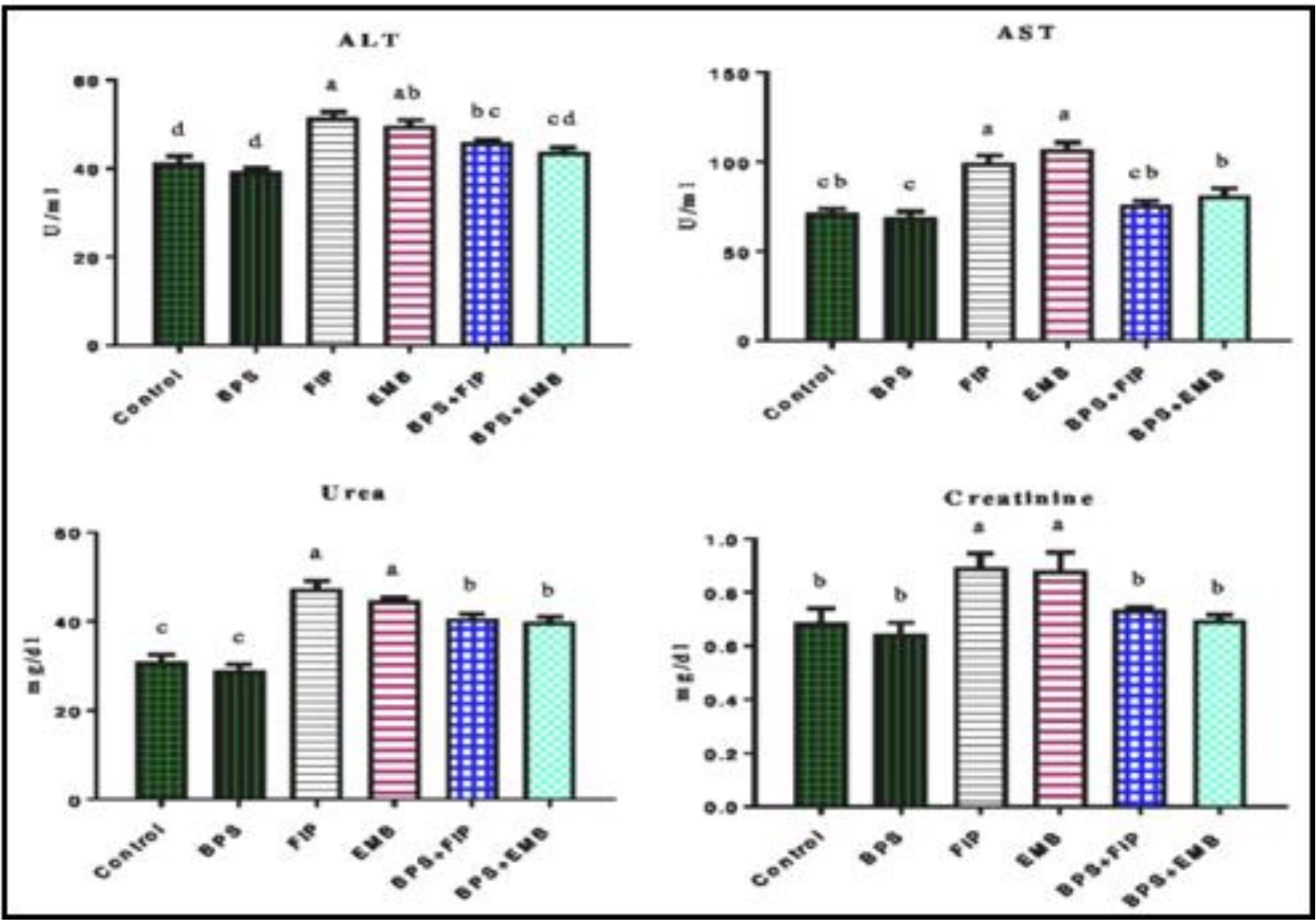

Fig. 1: Serum biochemical parameters of the different groups. Different letters indicate significant differences at $P<0.05$. BPS: Bee pollen suspension; FIP: Fipronil; EMB: Emamectin benzoate. 


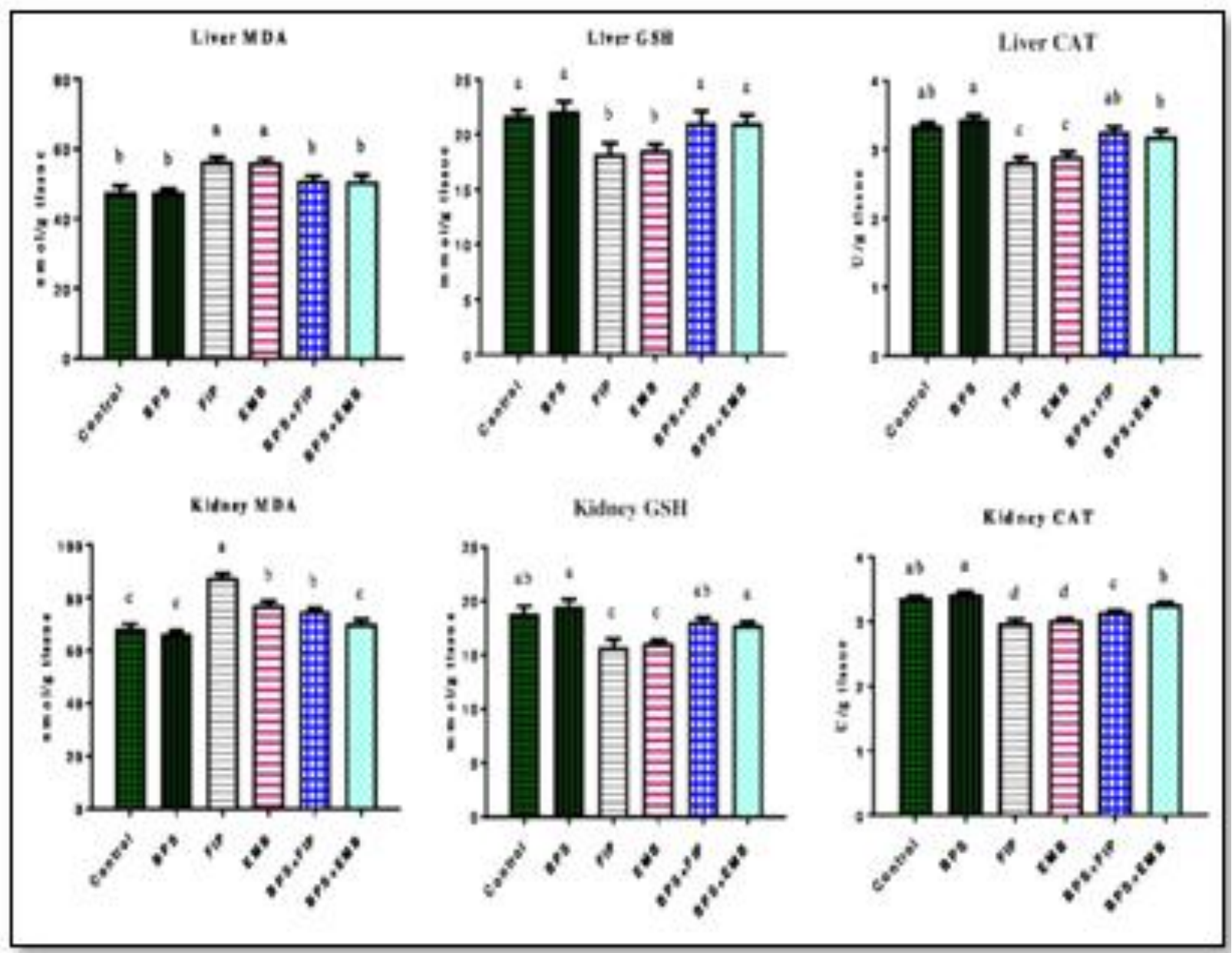

Fig. 2: Oxidant-antioxidant biomarkers in liver and kidney of the different groups. Different letters indicate significant differences at $P<0.05$. BPS: Bee pollen suspension; FIP: Fipronil; EMB: Emamectin benzoate.

\section{Histopathological findings:}

Liver of rats in control (Fig.3A) and BPS (Fig.3B) groups showed normal histological picture of central vein and hepatic parenchyma, while FIP administration induced hydropic degeneration of hepatocytes around central vein (Fig.3C). EMB caused congestion, edema in the portal area with coagulative necrosis and fatty infiltration in hepatocytes (Fig.3D). Liver sections of BPS+FIP (Fig.3E) and BPS+EMB rats (Fig.3F) showed marked improvement of hepatic architectures and somewhat normal hepatic parenchyma were seen in both groups. 


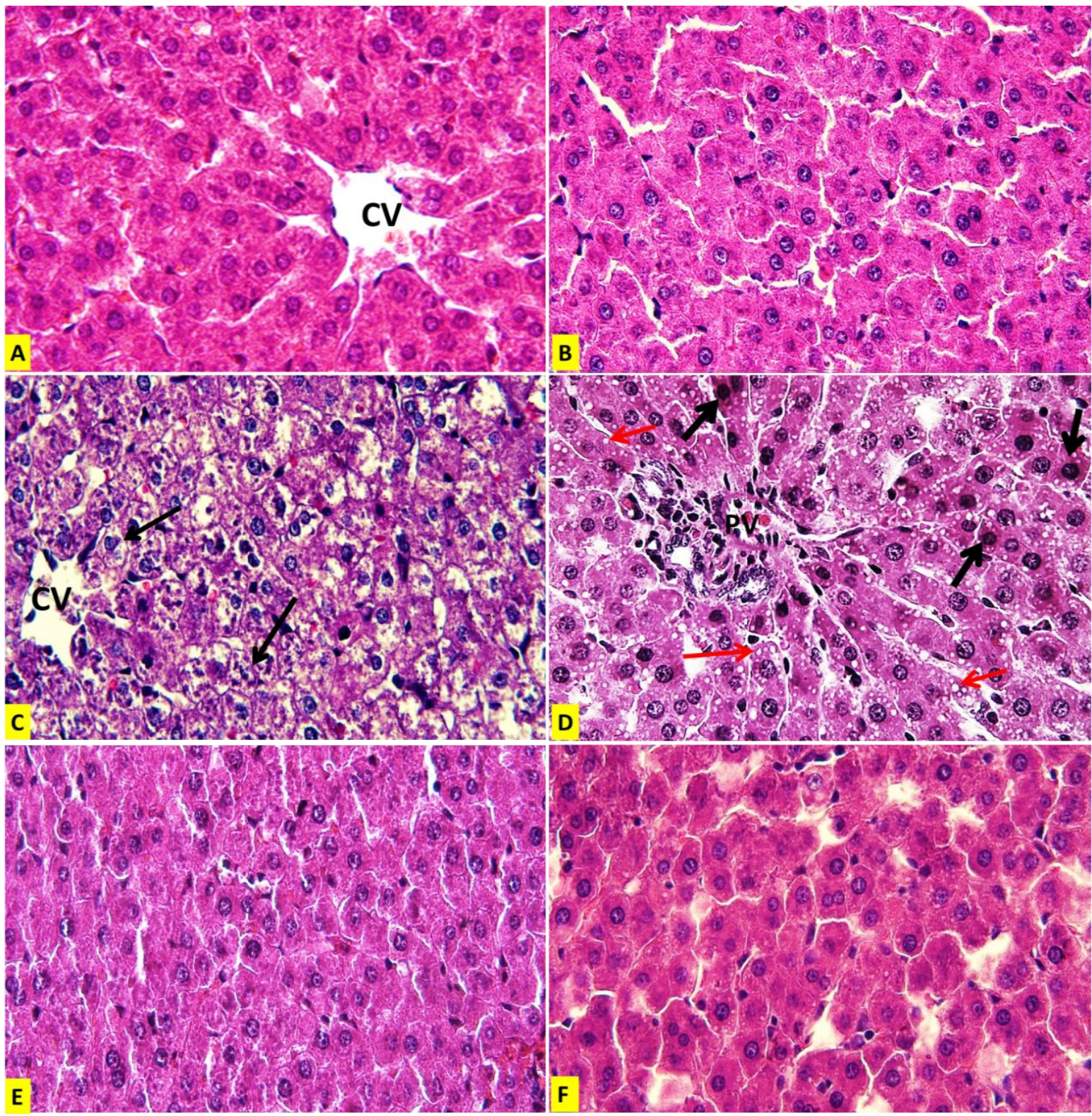

Fig. 3: Representative photomicrographs of liver sections of rats in different groups (H\&E stain $\left.X_{20}\right)$. (A): control and (B): BPS groups showing normal histological structure of hepatic parenchyma. (C): FIP group showing hydropic degeneration of hepatocytes around central vein (arrows). (D): EMB group showing congestion and edema in the portal area with coagulative necrosis of hepatocytes (black arrows) and fatty infiltration in hepatocytes (red arrows). (E): BPS+FIP group showing somewhat normal hepatic parenchyma. (F): BPS+EMB group showing more or less normal hepatocytes.

Kidneys of control (Fig. 4A) and BPS (Fig. 4B) groups showed normal structure. Sections of FIPintoxicated rats showed atrophied glomerular tuft, widening of Bowman's space, hyaline casts of most proximal and distal convoluted tubules (Fig. 4C1), sever vacuolar degeneration of renal epithelium of collecting tubules with fibrous tissue formation in between renal tubules (Fig. 4C2) and interstitial connective tissue proliferation with hyperplasia of fibrocytesin between collecting tubules (Crossman trichrome stain X20) (Fig. 4C3). Kidneys of EMBintoxicated rats showed congestion of glomeruli and interstitial tissue and necrotic renal tubules (Fig. 4D1) and interstitial hemorrhage between degenerated medullary tubules (Fig. 4D2). However, Pretreatment with BPS improved the observed alterations caused by FIP (Fig. 4E) or EMB (Fig. 4F). 


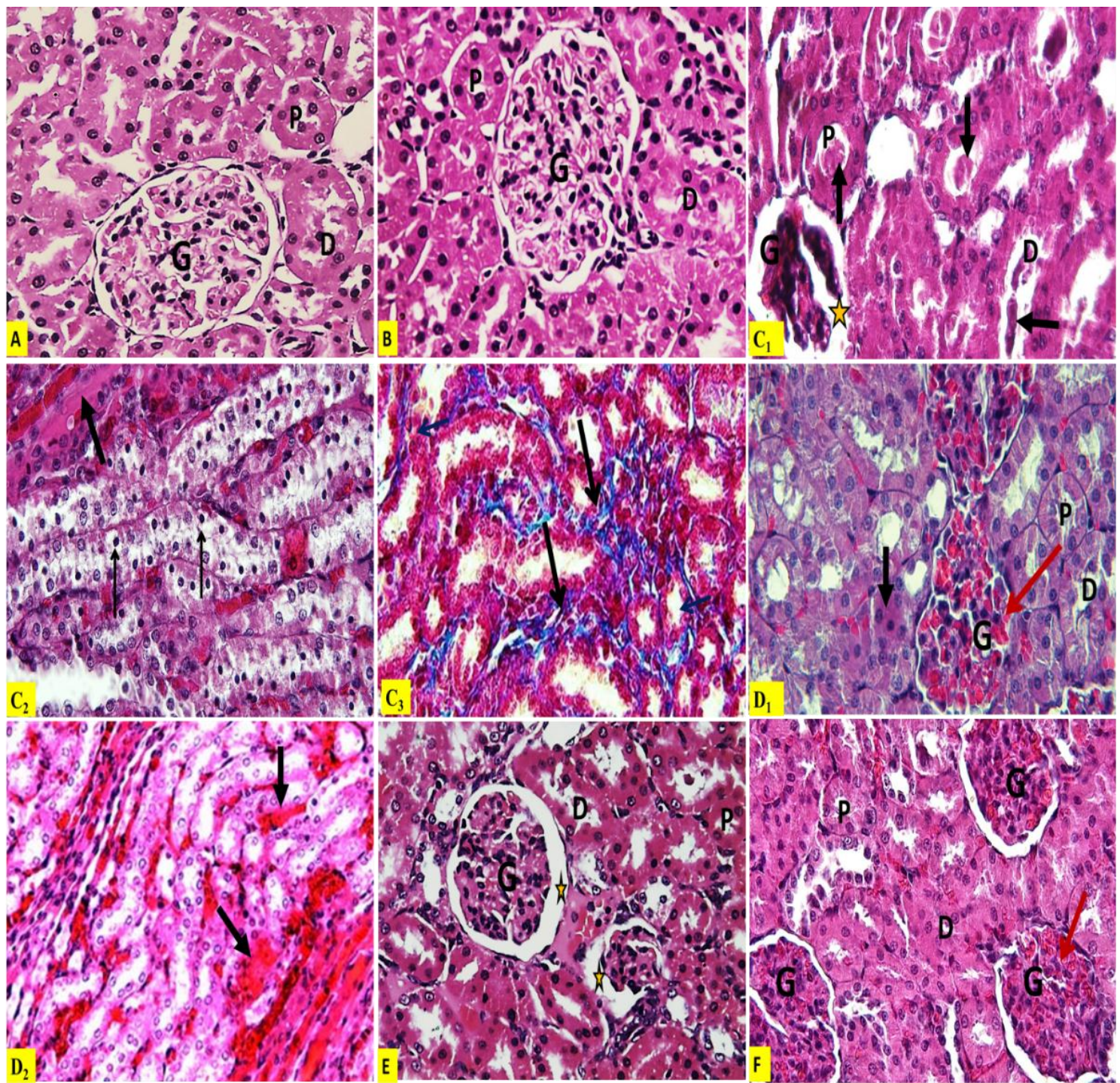

Fig. 4: Representative photomicrographs of Kidney sections of rats in different groups (H\&E stain X20 and C3 by Crossman trichrome stain X20). (A): control and (B): BPS groups showing normal structure of glomeruli $(\mathrm{G})$, proximal (P) and distal convoluted tubules (D). (C): FIP groups showing atrophied glomerular tuft and widening of Bowman's space (star) and hyaline casts of most proximal and distal convoluted tubules (arrows) (C1), sever vacuolar degeneration of renal epithelium of collecting tubules (thin arrows) with fibrous tissue formation in between renal tubules (thick arrow) (C2) and interstitial connective tissue proliferation with hyperplasia of fibrocytes in-between collecting tubules (arrows) (C3). (D): EMB group showing congestion of glomeruli and interstitial tissue (red arrow) and necrotic renal tubules (black arrow) (D1) and interstitial hemorrhage between degenerated medullary tubules (arrow) (D2). (E): BPS+FIP group showing normal kidney tissue with mild widening of Bowman's space of glomeruli (stars). (F): BPS+EMB group showing more or less normal kidney tissue with mild congestion of glomeruli (red arrow).

\section{DISCUSSION}

Environmental or occupational exposure to insecticides impacts animal and human life and exerts many deleterious effects. Fipronil and emamectin benzoate are relatively new and widely used insecticides causing adverse health effects via by oxidative stress mechanism (El-Sheikh and Galal, 2015; Kartheek and David, 2018). The crucial role of the liver and kidneys in the metabolism of xenobiotics, predisposes them to toxic cellular damages leading to liver and kidney dysfunction (O’Shaunessy, 2010).

Evaluation of serum and tissue biomarkers along with the histopathological changes have a higher predictive value in assessment of the hepatic and renal toxic effects of insecticides and may help in evaluation of the potential ameliorative role of the natural antioxidant against such toxic insults. Therefore, this study was designed to evaluate the potential protective role of BPS against FIP- and EMB- induced hepato-renal toxicity in rats. 
In the present study, oral administration of FIP and EMB to rats for 2 months provoked significant elevations in serum ALT and AST activities; urea and creatinine levels as previously reported by (AbdelHafez and Osman, 2013; Mossa et al., 2015; Khaldoun-Oularb et al., 2015, 2016; Abdel-Daim and Abdeen, 2018). The aforementioned results reflectthe increase in membrane permeability of the damaged hepatocytes (Plaa and Hewitt, 1982) and the reduction in the glomerular filtration in kidney (Walmsley and White, 1994) that may be attributed mainly to the recorded peroxidative effects of FIP and EMB.

Oxidative stress, the pro-oxidant/antioxidant imbalance, leads to oxidation of lipids, proteins and DNA in the cells and hence, tissue damage. It usually occurs due to ROS overproduction and reduction of the intracellular antioxidants resulting in lipid peroxidation, alternations in membrane permeability, DNA damage and different biochemical and histopathological alterations (Sies et al., 1991).

FIP and EMB induce oxidative stress in different organs. FIP causes uncoupling of oxidative phosphorylation leading to inhibition of electron flow through the electron transport chain and resulting in severe ATP depletion with over accumulation of $\mathrm{O}_{2}$ at levels that overwhelm the cell (Vidau et al., 2011). $\mathrm{H}_{2} \mathrm{O}_{2}$ is then generated from $\mathrm{O}_{2}{ }^{-}$and further undergoes the Fenton reaction in the presence of transition metals $\left(\mathrm{Fe}^{2+}\right)$ to produce $\mathrm{OH}$, the strongest reactive radical among the ROS (Nordberg and Arnér, 2001; Avery, 2011). Avermectins, including emaectin and abamectine are substrates for Pglycoprotein-mediated drug efflux (Chinkel et al., 1994) that increases ROS production due to a higher ATP use and the need for higher rates of ATP synthesis (Lespine et al., 2008).

MDA, a lipid peroxidation product along with GSH and CAT, cellular antioxidants, are valuable biomarkers of oxidative tissue damage. Our findings revealed significant elevation of MDA level concomitantly with reductions of GSH content and CAT activity in liver and kidney of FIP- and EMBintoxicated rats. The accomplished results closely resembled to previous in vivo studies, which have confirmed the hepato-renal oxidative damages induced by FIP (Abdel-Daim and Abdeen, 2018) and EMB (El-Sheikh and Galal, 2015), that mainly attributed to their ability to generate free radicals and deplete intracellular antioxidants.

The above findings were confirmed by the observed histopathological changes. In accordance with our histopathological results, previous studies reported pathological changes in liver and kidney tissues of FIP- (Mossa et al., 2015; Abdel-Daim and Abdeen, 2018) and EMB- (Mahmoud and Mahmoud, 2010, Khaldoun-Oularbi et al., 2015, 2016) intoxicated rats.
Bee pollen, an apitherapeutic agent, is rich in proteins, carbohydrates, minerals, lipids, vitamins, phenolic substances, and significant quantities of antioxidant agents (Komosinska-Vassev et al., 2015). It possesses a wide range of biological properties including antimicrobial, antioxidant, antiinflammatory, anti-apoptotic, anti-carcinogenic properties (Komosinska-Vassev et al., 2015; Huang et al., 2017).

The current results approved the hepato-renal protective effect of BPS that confirmed by the marked reduction of serum ALT, AST activities and urea, creatinine levels as well as significant decrease in MDA level concurrently with elevation of GSH content and CAT activity in liver and kidney. In addition, BPS ameliorated the histopathological changes induced by FIP and EMB. The same findings were reported by Huang et al. (2017), who demonstrated the protective effect of bee pollen against cisplatin induced hepato-renal toxicity.

Moreover, bee pollen exhibited protective effect against oxidative tissue damages of $\mathrm{CCl}_{4}$ (Yildiz et al., 2013), cisplatin (Huang et al., 2017), aflatoxins (El- Borai et al., 2018) and fluoride (Al-Daihan and Bhat, 2019). This protective effect is probably due to its antioxidant property that could be attributed to its phenolic and flavenoids contents which can protect against lipid oxidation in the cell membrane by decreasing ROS production, scavenging free radicals and activating cellular antioxidant enzymes (Procházková et al., 2011).

In the light of the above findings we can conclude that, FIP and EMB induced hepato-renal oxidative damages together with histopathological changes in liver and kidney of intoxicated rats. Bee pollen ameliorated these toxic effects. Therefore, bee pollen can be used as a new therapeutic and preventive supplement against toxic effects a variety of insecticides.

\section{REFERENCES}

Abdel-Daim, M.M. and Abdeen, A. (2018): Protective effects of rosuvastatin and vitamin $\mathrm{E}$ against fipronil-mediated oxidative damage and apoptosis in rat liver and kidney. Food and Chemical Toxicology 114: 69-77.

Abdel-Hafez, H.F. and Osman, H.H. (2013): Effects of pyridalyl and emamectin benzoate on some biological and biochemical parameters of Spodopteralittoralis (Boisd.) and Albino rat. Egypt. Acad. J. biolog. Sci., 6 (3): 59-68 (2013).

Aebi, H. (1984): Catalase in vitro. Method. Enzymology, 105: 121-126.

Al-Daihan, S. and Bhat, R.S. (2019): Protective effect of bee pollen against sodium fluoride-induced hepatonephrotoxicity and serum electrolyte 
changes in rats. Research report Fluoride 52(1) 9-17.

Avery, S.V. (2011): Molecular targets of oxidative stress. Biochem. J. 434, 201-210.

Badgujar, C.P.; Pawar, N.N.; Chandratre, G.A.; Telang, A.G. and Sharma, A.K. (2015): Fipronil induced oxidative stress in kidney and brain of mice: Protective effect of vitamin E and vitamin C. Pesticide Biochemistry and Physiology, Volume 118, February 2015, Pages 10-18.

Bancroft, D.; Stevens, A. and Turner, R. (1996): Theory and practice of histological techniques. $4^{\text {th }}$ edition, Churchill Livingstone, Edinburgh, London, Melbourne.

Beutler, E.; Duron, O. and Kelly, B.M. (1963): Improved method for the determination of blood glutathione. J. Lab. Clin. Med., 61: 882888.

Bjorling-Poulsen, M.; Andersen, H.R. and Grandjean, $\quad P$. (2008): Potential developmental neurotoxicity of pesticides used in Europe. Env. Health; 7(50): 1-23.

Brassard, D.; Haddad, S. and Hill, E. (2011): US EPA BEAD Chemical Profile for Registration Review: Fipronil (PC Code: 129121).

Castanha Zanoli, J.C.; Maioli, M.A.; Medeiros, H.C.D. and Mingatto, F.E. (2012): Abamectin affects the bioenergetics of liver mitochondria: a potential mechanism of hepatotoxicity, Toxicol. In Vitro 26 (1): 51-56.

Chinkel, A.H.; Smit, J.J.; van Tellingen, O. (1994): Disruption of the mouse mdr1a P-glycoprotein gene leads to a deficiency in the blood-brain barrier and to increased sensitivity to drugs. Cell; 77: 491-502.

Crossman, G. (1937): A modification of Mallory's connective tissue stain with a discussion of the principals involved. Anat. Rec., 69: 33-83.

De Barros, A.L.; Bae, J.H.; Borges, C.S.; Rosa, J.L.; Cavariani, M.M.1.; Silva, P.V.; Pinheiro, P.F.F.; Anselmo-Franci, J.A. and Arena, A.C. (2017): Perinatal exposure to insecticide fipronil: effects on the reproductive system in male rats. Reprod. Fertil. Dev.; 29(6): 11301143.

De Barros, A.L.; Rosa, J.L.; Cavariani, M.M.1.; Borges, C.S.; Villela, E.; Silva, P.; Bae, J.H.; Anselmo-Franci, J.A. and Cristina Arena, A. (2016): In utero and lactational exposure to fipronil in female rats: Pregnancy outcomes and sexual development. J. Toxicol. Environ. Health part A; 79(6): 266-273.

De Oliveira, P.R.; Bechara, G.H. and Denardi, S.E. (2012): Genotoxic and mutagenic effects of fipronil on mice. Exp. Toxicol. Pathol.; 64(6): 569-573.

El-Bialy, B.E.; Abdeen, E.E.; EL-Borai, N.B. and ElDiasty, E.M. (2016): Experimental Studies on Some Immunotoxicological Aspects of Aflatoxins Containing Diet and Protective
Effect of Bee Pollen Dietary Supplement. P.J.B.S; 19(1): 26-35.

El-Borai, N.B.; El-Bialy, B.E.; Abd El Latif, A.S.; Mohamed, M.A. and El-Bahrawy, A.A. (2018): Possible role of bee pollen dietary supplement in remediation of hepato- and geno-toxic effects of aflatoxins in rats. World J. Pharm. Sci.; 6(3): 91-97.

El-Sheikh, E.A. and Galal, A.A. (2015): Toxic effects of sub-chronic exposure of male albino rats to emamectin benzoate and possible ameliorative role of Foeniculumvulgare essential oil. Environ. Toxicol. Pharmacol. 39(3): 1177-88.

Fawcett, J.K and Soctt, J.E. (1960): A rapid and precise method for the determination of urea. Journal of Clinical Pathology, 13(2): 156-159.

Gabr, G.A.; Soliman, G.A.; Abdulaziz, S.S.; AlKahtani, A.A. and Ali, B.E. (2015): Teratogenic Effects in Rat Fetuses Subjected to the Concurrent in utero Exposure to Emamectin Benzoate Insecticide. Pakistan Journal of Biological Sciences; 18 (7): 333340.

Huang, H.; Shen, Z.; Geng, Q.Wu, Z.; Shi, P. and Miao, X. (2017): Protective effect of Schisandrachinensis bee pollen extract on liver and kidney injury induced by cisplatin in rats. Biomed.Pharmacother. 95: 1765-1776.

Ioriatti, C.; Anfora, G.; Angeli, G.; Civolani, S.; Schmidt, S. and Pasqualini, E. (2009): Toxicity of emamectin benzoate to Cydiapomonella (L.) and Cydiamolesta (Busck) (Lepidoptera: Tortricidae): Laboratory and field tests. Pest Manag. Sci. 65: 306-312.

Jackson, D.; Cornell, C.B.; Luukinen, B.; Buhl, K. and Stone, D. (2009): Fipronil technical fact sheet. National Pesticide Information Center, Oregon State University extension services, http://npic.orst.edu/factsheets/archive/fiptech.h $\underline{\mathrm{tml}}$.

Jansson, R.K. and Dybas, R.A. (1997): Avermectins, biochemical mode of action, biological activity, and agricultural importance. In: "Insecticides with Novel Modes of Action: Mechanism and Application" (eds. I. Ishaaya, I. and D. Degheele), Springer, New York, pages 152-167.

Kartheek, R.M. and David, M. (2018): Assessment of fipronil toxicity on wistar rats: A hepatotoxic perspective. Toxicology Reports 5: 448-456.

Khaldoun-Oularbi, H.; Allorge, D.; Richeval, C.; Lhermitte, M. and Djenas, N. (2015): Emamectin benzoate (Proclaim ${ }^{\circledR}$ ) mediates biochemical changes and histopathological damage in the kidney of male Wistar rats (Rattusnorvegicus), Toxicologie Analytique et Clinique; 27(2): 72-80.

Khaldoun-Oularbi, H.; Richeval, C.; Lebaili, N.; Zerrouki-Daoudi, N.; Baha, M.; Djennas, N. and Allorge, D. (2016): Ameliorative effect of vitamin $\mathrm{C}$ against hepatotoxicity induced by 
emamectin benzoate in rats. Human and Experimental Toxicology; 36 (7): 709-717.

Komosinska-Vassev, K.; Olczyk, P.; Kafmierczak, J.; Mencner, L. and Olczyk, K. (2015): Bee Pollen: Chemical Composition and Therapeutic Application, Review Article. Evidence-Based Complementary and Alternative Medicine, (2015), Article ID 297425, 6 pages.

Lespine, A.; Alvinerie, M. and Vercruysse, J. (2008): ABC transporter modulation: a strategy to enhance the activity of macrocyclic lactone anthelmintics. Trends Parasitol.; 24: 293-298.

Mahmoud, H.I. and Mahmoud, M.E. (2010): effect of thiamethoxam and emamectin benzoate on hematological, biochemical and histopathological parameters in female rats. J. Agric. Chemistry and Biotechnology, Mansoura Univ., Vol. (8): 457-472.

Mehraban, F.; Jafari, M.; Toori, M.A.; Sadeghi, H.; Joodi, B.; Mostafazade, M. and Sadeghi, H. (2014): Effects of date palm pollen (Phoenix dactylifera L.) and Astragalusovinus on sperm parameters and sex hormones in adult male rats. Iran J. Reprod Med. 12(10): 705-12.

Mossa, A.H.; Swelam, E.S. and Mohafrasha S.M.M. (2015): Sub-chronic exposure to fipronil induced oxidative stress, biochemical and histopathological changes in the liver and kidney of male albino rats. Toxicol Rep. 2: 775-784.

Noaishi, M.A.; Aify, M.M. and Abd Allah, A.A. (2013): Study the inhalation exposure effect of pesticide mixture in the white rat. Nat. Sci. 11(7): 45-54.

Nordberg, J. and Arnér, E.S.J. (2001): Reactive oxygen species, antioxidants, and the mammalian thioredoxin system. Free Radic. Biol. Med. 31, 1287-1312.

O'Shaunessy, K. (2010): Principles of Clinical Pharmacology and Drug Therapy. In: Warrel D., Cox T., Firth J., editors. Oxford Textbook of Medicine.5th ed. Vol. 1. Oxford University Press; Oxford, UK: pp. 1450-1476.

Ohkawa, H.; Ohishi, N. and Yagi, K. (1979): Assay for lipid peroxides in animal tissues by thiobarbituric acid reaction. Analytical Biochemistry, 95: 351-358.

Plaa, G.L. and Hewitt, W.R. (1982): Detection and evaluation of chemically induced liver injury.
In: Hayes, W., Principles and Methods of Toxicology. Raven Press, New York, pp: 407.

Procházková, D.; Boušová, I. and Wilhelmová, N. (2011): Antioxidant and prooxidant properties of flavonoids. Review. Fitoterapia. 2011; 82: 513-523.

Reitman, S. and Frankel, S. (1957): Colorimetric determination of serum oxalacetic and glutamic pyruvic transaminase. Amer. J. Clin. Pathol., 28: 56-63.

Schirmeister, J. (1964): Determination of creatinine level. Dtsch. Med. Wschr., 89: 1940-1947.

Sies, H. (1991): Oxidative stress: Oxidants and antioxidants, PP. XV-XXII, Academic press, London.

Stanley, E.M.; Wilson, M.A. and Fadel, J.R. (2012): Hippocampal neurotransmitter efflux during one-trial novel object recognition in rats. Neurosci. Lett. 511: 38-42.

Tingle, C.C.; Rother, J.A.; Dewhurst, C.F.; Lauer, S. and King, W.J. (2003): Fipronil: environmental fate, ecotoxicology, and human health concerns. Rev Environ Contam. Toxicol.;176: 1-66.

Vidau, C.; González-Polo, R.A.; Niso-Santano, M.; Gómez-Sánchez, R.; Bravo-San Pedro, J.M.; Pizarro-Estrella, E.; Blasco, R.; Brunet, J.L.; Belzunces, L.P. and Fuentes, J.M. (2011): Fipronil is a powerful uncoupler of oxidative phosphorylation that triggers apoptosis in human neuronal cell line SHSY5Y.Neurotoxicology 32, 935-943.

Walmsley, R.N. and White, G.H. (1994): A Guide to Diagnostic Clinical Chemistry. $3^{\text {rd }}$ ed., Blackwell Scientific Publication, London.

Wise, L.D.; Allen, H.L.; Hoe, C.M.; Verbeke, D.R. and Gerson, R.J. (1997): Developmental neurotoxicity evaluation of the avermectin pesticide, emamectin benzoate, in SpragueDawley rats. Neurotoxicol. Teratol.;19(4): 315-26.

Yıldız, O.; Can, Z.; Saral, O.; Yuluğ, E.; Oztürk, F.; Aliyazıcıoğlu, R.; Canpolat, S. and Kolaylı, S. (2013): Hepatoprotective potential of chestnut bee pollen on carbon tetrachloride-induced hepatic damages in rats. Evid. Based Complement Alternat. Med.; 2013: 461-478. 


\section{تخفيف التأثيرات السامة الكبدية والكلوية للفيبرونيل والايماميكتين بنزوات في الفئران بإستخدام حبوب اللقاح

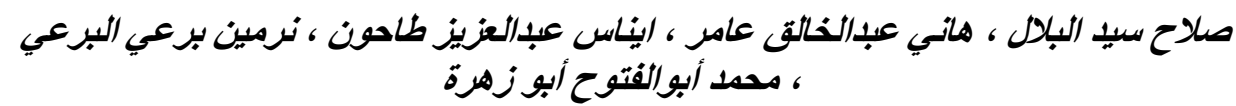

E-mail: nermeenborai@yahoo.com Assiut University web-site: www.aun.edu.eg

أدي الاستخدام المكثف للمبيدات إلي تلوث البيئة والإضرار بصحة الإنسان والحيوان. الفيبرونيل والايماميكتين بنزوات، مبيدات

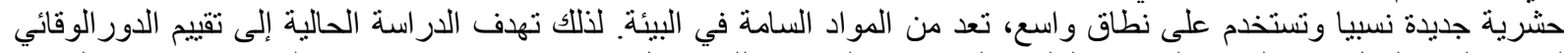

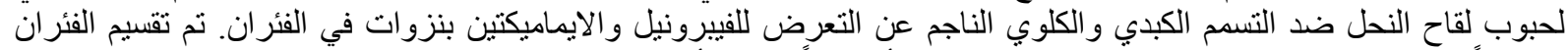

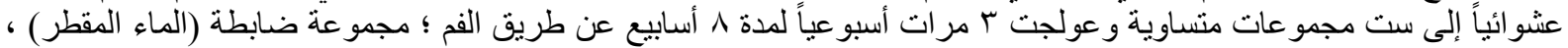

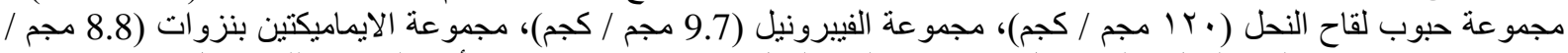

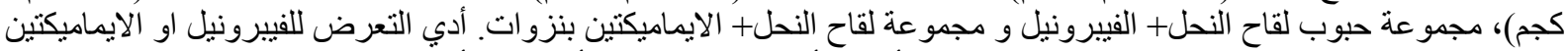

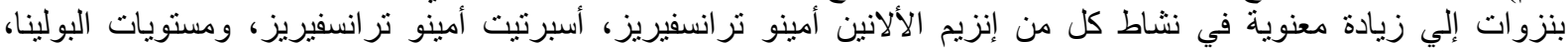

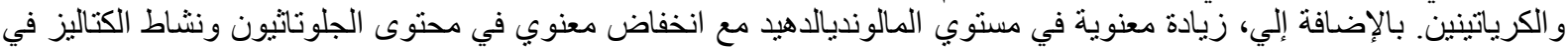

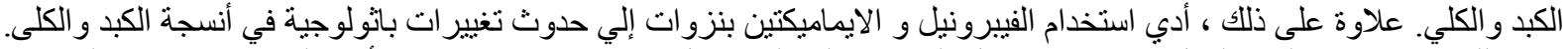

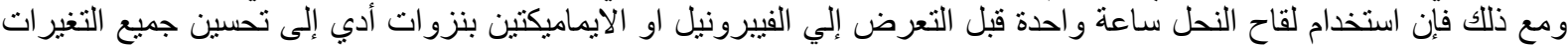

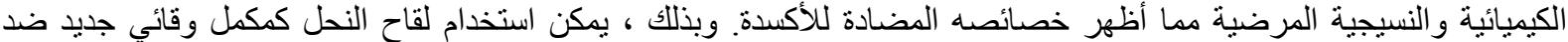

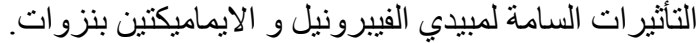

